\title{
Fixed-dose combination: beware of its limitations
}

\author{
NEELESH GUPTA, ${ }^{1}$ MOHAMMED ELKHAZENDAR, ${ }^{2}$ RAJEEV GUPTA ${ }^{3}$ \\ 1 Department of Medicine, Nazareth Hospital, Philadelphia, PA, USA \\ 2 Clinical Sciences Department, College of Medicine, University of Sharjah, United Arab Emirates \\ ${ }^{3}$ Department of Cardiology, Mediclinic Al Jowhara Hospital, Al Ain, United Arab Emirates
}

We read with great interest the editorial detailing the likelihood of cardiovascular (CV) benefit from the triple fixed-dose combination (FDC) therapy for patients with type 2 diabetes mellitus. ${ }^{1}$ Sodiumglucose cotransporter-2 inhibitors (SGLT2i) are preferred in view of their documented $\mathrm{CV}$ benefits. The FDC pill containing metformin, dipeptidyl peptidase-4 (DPP-4) inhibitor and SGLT2i has been approved by the US FDA. However, the CV protective effects of SGLT2i may be less when combined with metformin. For instance, with canagliflozin, the risk of CV death and hospitalisation was reduced by $36 \%$ in metformin non-users versus $12 \%$ in metformin users $(p=0.03) .{ }^{2}$ Although this may well be a type 1 statistical error, notably, a similar trend was also observed with empagliflozin (53\% vs $32 \%, p=0.01) .{ }^{3}$ A possible explanation may be that the use of metformin has its well-documented CV benefits; thus, additional benefits were minimised with the added use of SGLT2i. ${ }^{4}$ Interestingly, the addition of a DPP-4 inhibitor to metformin resulted in improved CV outcomes compared with the initiation of DPP-4 inhibitor in non-metformin users. ${ }^{5}$ Therefore, the issue deserves further investigation, perhaps as an endpoint in a future CV outcome trial with an SGLT2i.

\section{Conflict of interest None. Funding None}

\section{References}

1. Ryder REJ, Abdul-Ghani MA, DeFronzo RA. Diabetes medications with cardiovascular protection: the likelihood of benefit from combination therapy increases further following new evidence during 2020. Br J Diabetes 2020; 20(2):85-8. https://doi.org/10.15277/bjd.2020.276

2. Rådholm K, Figtree G, Perkovic V, et al. Canagliflozin and heart failure in type 2 diabetes mellitus: results from the CANVAS program. Circulation 2018;138(5):458-68. https://doi.org/10.1161/circulationaha.118.034222

3. Inzucchi SE, Fitchett $D$, Jurišić-Eržen $D$, et al. Are the cardiovascular and kidney benefits of empagliflozin influenced by baseline glucose-lowering therapy? Diabetes Obes Metab 2020;22(4):631-9. https://doi.org/10.1111/ dom.13938

4. Han $Y$, Xie H, Liu Y, et al. Effect of metformin on all-cause and cardiovascular mortality in patients with coronary artery diseases: a systematic review and an updated meta-analysis. Cardiovasc Diabetol 2019:18(1):96. https://doi.org/10.1186/s12933-019-0900-7

5. Crowley MJ, Gokhale M, Pate V , et al. Impact of metformin use on the cardiovascular effects of dipeptidyl peptidase-4 inhibitors: an analysis of Medicare claims data from 2007 to 2015. Diabetes Obes Metab 2019;21(4): 854-65. https://doi.org/10.1111/dom.13589

Correspondence: Dr Mohammed Elkhazendar Clinical Sciences Department, College of Medicine, University of Sharjah, United Arab Emirates E-mail: modnnkh@yahoo.com

Br J Diabetes 2021;21:157 https://doi.org/10.15277/bjd.2021.289 